\title{
Dynamic Model of a Wind Turbine for the Electric Energy Generation
}

\author{
José de Jesús Rubio, ${ }^{1}$ Luis Arturo Soriano, ${ }^{2}$ and Wen $Y u^{2}$ \\ ${ }^{1}$ Sección de Estudios de Posgrado e Investigación, ESIME Azcapotzalco, Instituto Politécnico Nacional, \\ Avenida de las Granjas No. 682, Colonia Santa Catarina, 02250 México, DF, Mexico \\ ${ }^{2}$ Departamento de Control Automatico, CINVESTAV, Instituto Politécnico Nacional, 07360 México, DF, Mexico
}

Correspondence should be addressed to José de Jesús Rubio; jrubioa@ipn.mx

Received 5 November 2013; Accepted 7 January 2014; Published 26 February 2014

Academic Editor: Feng Ding

Copyright (C) 2014 José de Jesús Rubio et al. This is an open access article distributed under the Creative Commons Attribution License, which permits unrestricted use, distribution, and reproduction in any medium, provided the original work is properly cited.

A novel dynamic model is introduced for the modeling of the wind turbine behavior. The objective of the wind turbine is the electric energy generation. The analytic model has the characteristic that considers a rotatory tower. Experiments show the validity of the proposed method.

\section{Introduction}

Researchers are often trying to improve the total power of a wind turbine. The dynamic model of a wind turbine plays an important role in some applications as the control, classification, or prediction.

Some authors have proposed the equations to model the dynamic behavior of the wind turbine as shown in [1-5].

This paper presents a novel dynamic model of a wind turbine; the first dynamic model is for the wind turbine, the second is for the tower, and both are related. Because the rotatory tower can turn, it may help the wind turbine to increase the air intake. Some companies propose wind turbines that consider rotatory blades; however, in this study, a rotatory tower is proposed instead of the rotatory blades because the first dynamic model is easier to obtain than the second.

The proposed model is linear in the states as the works analyzed by [6-10] show. The technique provides an acceptable approximation of the wind turbine behavior.

The paper is structured as follows. In Section 2, the dynamic model of a windward wind turbine of three blades with a rotatory tower is introduced. In Section 3, the simulations of the dynamic model are compared with the real data obtained by a real wind turbine prototype. Finally, in Section 4 , the conclusion and future research are detailed.

\section{Dynamic Model of the Wind Turbine with a Rotatory Tower}

This section is divided into four parts: the first is the description of the mechanic model, the second is the description of the aerodynamic model, the third is the description of the electric model, and, finally, the fourth is the combination of the aforementioned models to obtain the final dynamic model.

The dynamic model of the wind turbine is, first, the equations that represent the change between the wind energy and mechanic energy and, second, the equations that represent the change between the mechanic energy and electric energy.

2.1. The Mechanic Model. A windward wind turbine of three blades with a rotatory tower is considered. First, the Euler Lagrangian method $[11,12]$ is used to obtain the model that represents the change from the wind energy to mechanic energy for the wind turbine and the change from the electric energy to mechanic energy for the tower. The masses are 


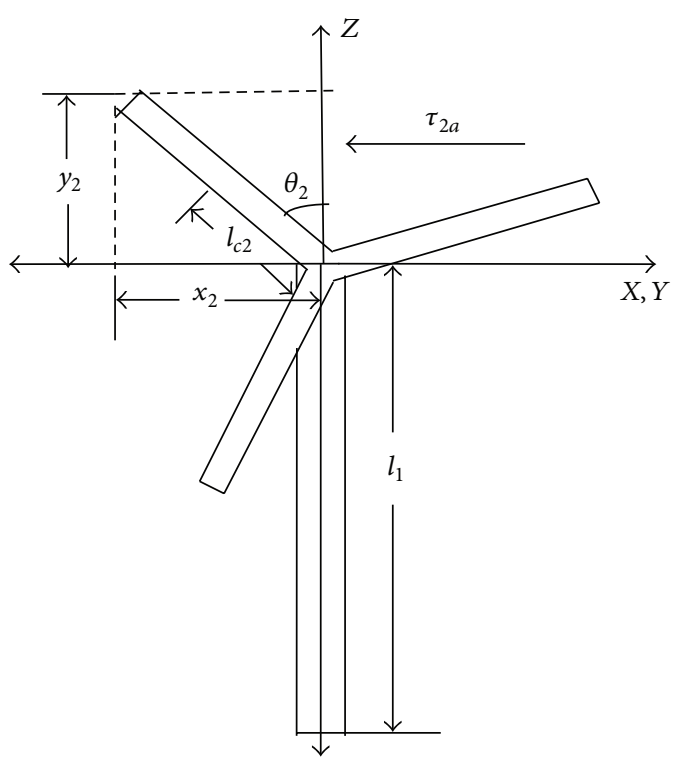

FIGURE 1: Lateral view of the wind turbine.

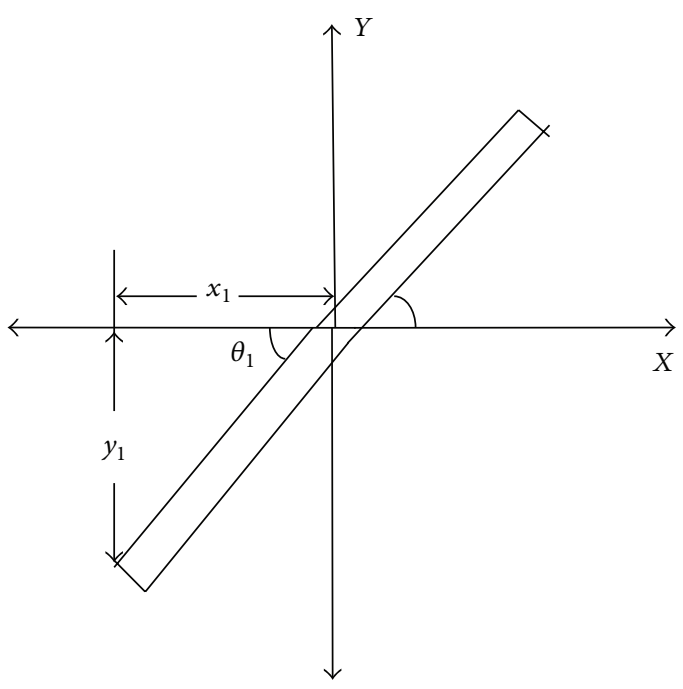

FIGURE 2: Upper view of the wind turbine.

concentrated at the center of mass. Consider the lateral view of Figure 1 and upper view of Figure 2.

From Figures 1 and 2, it can be seen that

$$
\begin{gathered}
x_{2}=-l_{c 2} S_{2}\left(-C_{1}\right)=l_{c 2} S_{2} C_{1}, \\
y_{2}=-l_{c 2} S_{2}\left(-S_{1}\right)=l_{c 2} S_{2} S_{1},
\end{gathered}
$$

where $S_{1}=\sin \left(\theta_{1}\right), S_{2}=\sin \left(\theta_{2}\right), C_{1}=\cos \left(\theta_{1}\right), C_{2}=\cos \left(\theta_{2}\right)$, $\theta_{1}$ is the angular position of the tower motor in $\operatorname{rad}, \theta_{2}$ is the angular position of a wind turbine blade in $\mathrm{rad}$, and $l_{c 2}$ is the length to the center of the wind turbine blade in $m$.
Consequently, the kinetic energy $K_{1}, K_{2}$ and potential energy $P_{1}, P_{2}$ are given as

$$
\begin{gathered}
K_{1}=0, \\
K_{2}=\frac{1}{2} m_{2} l_{c 2}^{2} S_{2}^{2} \dot{\theta}_{1}^{2}+\frac{1}{2} m_{2} l_{c 2}^{2} \dot{\theta}_{2}^{2}, \\
P_{1}=m_{1} g l_{c 1}, \\
P_{2}=l_{1}+m_{2} g l_{c 2} C_{2},
\end{gathered}
$$

where $m_{1}$ is the tower mass in $\mathrm{kg}, m_{2}$ is the blade mass in $\mathrm{kg}, g$ is the acceleration gravity in $\mathrm{m} / \mathrm{s}^{2}, l_{1}$ is the constant length of the tower in $\mathrm{m}$, and $l_{c 1}$ is the length to the center of the tower in $\mathrm{m}$. The torques $\tau_{T 1 a}$ and $\tau_{T 2 a}$ are given as

$$
\begin{aligned}
& \tau_{T 1 a}=\tau_{1 a}-k_{b 1} \theta_{1}-b_{b 1} \dot{\theta}_{1}, \\
& \tau_{T 2 a}=\tau_{2 a}-k_{b 2} \theta_{2}-b_{b 2} \dot{\theta}_{2},
\end{aligned}
$$

where $\tau_{2 a}$ is the torque of the generator moved by the blade in $\mathrm{kg} \mathrm{m}^{2} \mathrm{rad} / \mathrm{s}^{2}, \tau_{1 a}$ is the torque of the motor used to move the tower in $\mathrm{kg} \mathrm{m}{ }^{2} \mathrm{rad} / \mathrm{s}^{2}, k_{b 1}$ and $k_{b 2}$ are the spring effects presented when the blade is near to a stop in $\mathrm{kg} \mathrm{m}^{2} / \mathrm{s}^{2}$, and $b_{b 1}$ and $b_{b 2}$ are the shock absorbers in $\mathrm{kg} \mathrm{m}^{2} \mathrm{rad} / \mathrm{s}$. Using the Euler Lagrange method in $[11,12]$ gives the following equations:

$$
\begin{gathered}
m_{2} l_{c 2}^{2} S_{2}^{2} \ddot{\theta}_{1}+2 m_{2} l_{c 2}^{2} S_{2} C_{2} \dot{\theta}_{1} \dot{\theta}_{2}+b_{b 1} \dot{\theta}_{1}+k_{b 1} \theta_{1}=\tau_{1 a}, \\
m_{2} l_{c 2}^{2} \ddot{\theta}_{2}+m_{2} g l_{c 2} S_{2}+b_{b 2} \dot{\theta}_{2}+k_{b 2} \theta_{2}=\tau_{2 a} .
\end{gathered}
$$

The angular position of the blade 1 is related to the angular position of the blades 2 and 3 as follows:

$$
\begin{aligned}
& \theta_{3}=\theta_{2}+\frac{2}{3} \pi \mathrm{rad}, \\
& \theta_{4}=\theta_{2}+\frac{4}{3} \pi \mathrm{rad},
\end{aligned}
$$

where $\theta_{3}$ and $\theta_{4}$ are the angular positions for the blades 2 and 3 , respectively. Then, using (4), it yields the equations for blades 2 and 3 as a function of $\theta_{2}$ as follows:

$$
\begin{gathered}
m_{2} l_{c 2}^{2} S_{2+(2 / 3) \pi}^{2} \ddot{\theta}_{1}+2 m_{2} l_{c 2}^{2} S_{2+(2 / 3) \pi} C_{2+(2 / 3) \pi} \dot{\theta}_{1} \dot{\theta}_{2} \\
+b_{b 1} \dot{\theta}_{1}+k_{b 1} \theta_{1}=\tau_{1 b}, \\
m_{2} l_{c 2}^{2} \ddot{\theta}_{2}+m_{2} g l_{c 2} S_{2+(2 / 3) \pi}+b_{b 2} \dot{\theta}_{2}+k_{b 2}\left(\theta_{2}+\frac{2}{3} \pi\right)=\tau_{2 b}, \\
m_{2} l_{c 2}^{2} S_{2+(4 / 3) \pi}^{2} \ddot{\theta}_{1}+2 m_{2} l_{c 2}^{2} S_{2+(4 / 3) \pi} C_{2+(4 / 3) \pi} \dot{\theta}_{1} \dot{\theta}_{2} \\
+b_{b 1} \dot{\theta}_{1}+k_{b 1} \theta_{1}=\tau_{1 c}, \\
m_{2} l_{c 2}^{2} \ddot{\theta}_{2}+m_{2} g l_{c 2} S_{2+(4 / 3) \pi}+b_{b 2} \dot{\theta}_{2}+k_{b 2}\left(\theta_{2}+\frac{4}{3} \pi\right)=\tau_{2 c},
\end{gathered}
$$

where $\tau_{1 b}, \tau_{2 b}, \tau_{1 c}$, and $\tau_{2 c}$ are the torques applied to move the blades 2 and 3 , respectively. Adding $S_{2}^{2}+S_{2+(2 / 3) \pi}^{2}+S_{2+(4 / 3) \pi}^{2}$, 
$S_{2} C_{2}+S_{2+(2 / 3) \pi} C_{2+(2 / 3) \pi}+S_{2+(4 / 3) \pi} C_{2+(4 / 3) \pi}$, and $S_{2}+S_{2+(2 / 3) \pi}+$ $S_{2+(4 / 3) \pi}$, respectively, it gives

$$
\begin{gathered}
S_{2}^{2}+S_{2+(2 / 3) \pi}^{2}+S_{2+(4 / 3) \pi}^{2}=1.5 \\
S_{2} C_{2}+S_{2+(2 / 3) \pi} C_{2+(2 / 3) \pi}+S_{2+(4 / 3) \pi} C_{2+(4 / 3) \pi}=0 \\
S_{2}+S_{2+(2 / 3) \pi}+S_{2+(4 / 3) \pi}=0 .
\end{gathered}
$$

Now, adding the three equations of (4), (6), and (7) and using (8), (9), and (10), it gives

$$
\begin{gathered}
4.5 m_{2} l_{c 2}^{2} \ddot{\theta}_{1}+3 b_{b 1} \dot{\theta}_{1}+3 k_{b 1} \theta_{1}=\tau_{1}, \\
3 m_{2} l_{c 2}^{2} \ddot{\theta}_{2}+3 b_{b 2} \dot{\theta}_{2}+3 k_{b 2} \theta_{2}+2 \pi k_{b 2}=\tau_{2},
\end{gathered}
$$

where $\tau_{1}=\tau_{1 a}+\tau_{1 b}+\tau_{1 c}$ and $\tau_{2}=\tau_{2 a}+\tau_{2 b}+\tau_{2 c}$. From Figures 1 and $2, \tau_{2}$ of (11) is defined as follows:

$$
\begin{gathered}
\tau_{2}=C_{1} F_{2}, \\
F_{2}=F_{2 a}+F_{2 b}+F_{2 c},
\end{gathered}
$$

where $C_{1}=\cos \left(\theta_{1}\right) F_{2 a}$ and $F_{2 b}$ and $F_{2 c}$ are the force of the air received by the three blades. Equation (12) describes the assumption that the air goes in one direction; if $\theta_{1}=0$, then the maximum air intake moves the blades of the wind turbine, but if the tower turns to the left or to the right and $\theta_{1}$ changes, then the wind turbine turns and the air intake decreases. From Figures 1 and 2 and [12], $\tau_{1}$ of (11) is defined as follows:

$$
\tau_{1}=k_{m} i_{1}
$$

where $k_{m}$ is a motor magnetic flux constant of the tower in $\mathrm{Wb}$ and $i_{1}$ is the motor armature current of the tower in A. Equations (11), (12), and (13) are the main equations of the mechanic model that represents the wind turbine and tower.

2.2. Aerodynamic Model. The aerodynamic model is the dynamic model of the torque applied to the blades. The mechanic power captured by the wind turbine $P_{a}$ is given by [2-5]

$$
P_{a}=F_{2 a} \dot{\theta}_{2}=\frac{1}{2} \rho A C_{p}(\lambda, \beta) V_{\omega}^{3}
$$

where $\rho$ is the air density in $\mathrm{Kg} / \mathrm{m}^{3}, A=\pi R^{2}$ is the area swept by the rotor blades in $\mathrm{m}^{2}$ with radius $R$ in $\mathrm{m}, V_{\omega}$ is the wind speed in $\mathrm{m} / \mathrm{s}$, and $C_{p}(\lambda, \beta)$ is the performance coefficient of the wind turbine, whose value is a function of the tip speed ratio $\lambda$, defined as [2-5]

$$
\lambda=\frac{\dot{\theta}_{2} R}{V_{\omega}} .
$$

For the purpose of simulation, the following model of $C_{p}(\lambda, \beta)$ is presented [2-5]:

$$
C_{p}(\lambda, \beta)=c_{1}\left(\frac{c_{2}}{\lambda_{i}}-c_{3} \beta-c_{4}\right) e^{-c_{5} / \lambda_{i}}+c_{6} \lambda,
$$

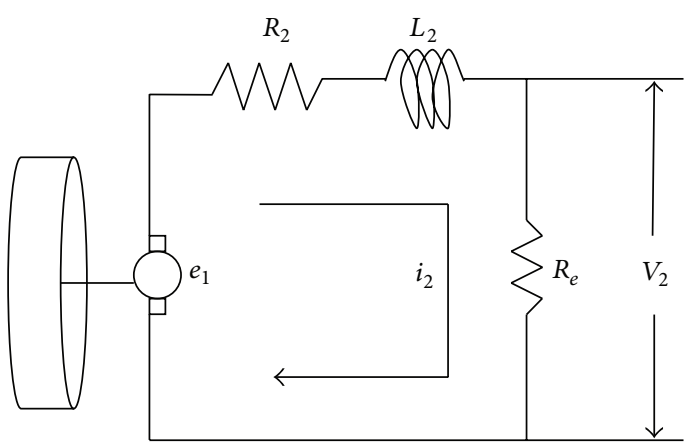

FIgURE 3: The wind turbine generator.

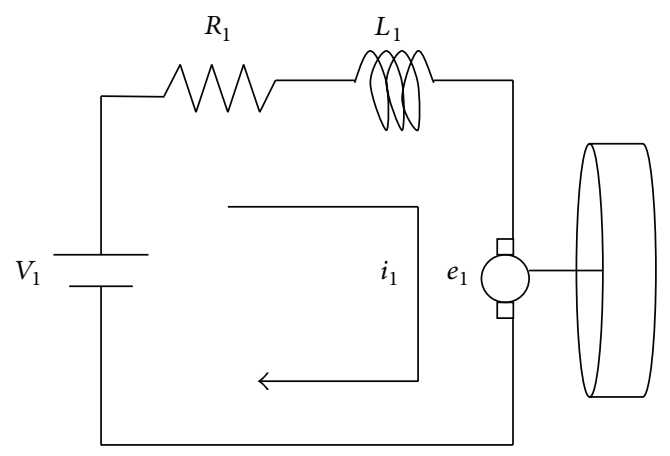

Figure 4: The tower motor.

where

$$
\frac{1}{\lambda_{i}}=\frac{1}{\lambda+0.08 \beta}-\frac{0.035}{\beta^{3}+1}
$$

and the coefficients are $c_{1}=0.5176, c_{2}=116, c_{3}=0.4, c_{4}=5$, $c_{5}=21, c_{6}=0.0068$, and $\beta$ is the blade pitch angle in rad. Using (12), (14), (15), (16), and (17) gives the dynamic model of the torque applied to the wind turbine blades as follows:

$$
\begin{aligned}
& \tau_{2}=C_{1}\left(F_{2 a}+F_{2 b}+F_{2 c}\right), \\
& F_{2 a}=\frac{1}{2 \dot{\theta}_{2}} \rho A C_{p}(\lambda, \beta) V_{\omega}^{3}, \\
& F_{2 b}=\frac{1}{2 \dot{\theta}_{2}} \rho A C_{p}(\lambda, \beta) V_{\omega}^{3}, \\
& F_{2 c}=\frac{1}{2 \dot{\theta}_{2}} \rho A C_{p}(\lambda, \beta) V_{\omega}^{3},
\end{aligned}
$$

where $C_{1}$ is defined in (12), $\lambda$ is defined in (15), $C_{p}(\lambda, \beta)$ is defined in (16), and $\lambda_{i}$ is defined in (17).

2.3. The Electric Model. Now, analyze the change from the mechanic to electric energy for the wind turbine generator and the electric energy to mechanic energy for the tower motor. Figure 3 shows the wind turbine generator and Figure 4 shows the tower motor.

In $[12,13]$, they presented the model of a motor, and similarly, from Figure 3, a model for the generator is obtained 
by using the Kirchhoff voltage law. Therefore, the dynamic models of the motor and generator are as follows:

$$
\begin{aligned}
& V_{1}=R_{1} i_{1}+L_{1} \dot{i}_{1}+k_{1} \dot{\theta}_{1}, \\
& k_{2} \dot{\theta}_{2}=R_{2} i_{2}+L_{2} \dot{i}_{2}+V_{2},
\end{aligned}
$$

where $k_{1}$ is the motor back emf constant in $\mathrm{V} \mathrm{s} / \mathrm{rad}, k_{2}$ is the generator back emf constant in $\mathrm{V} \mathrm{s} / \mathrm{rad}, R_{1}$ is the motor armature resistance in $\Omega, R_{2}$ is the generator armature resistance in $\Omega, L_{1}$ is the motor armature inductance in $\mathrm{H}$, $L_{2}$ is the generator armature inductance in $\mathrm{H}, V_{1}$ is the motor armature voltage in $\mathrm{V}, V_{2}$ is the generator armature voltage in $\mathrm{V}, i_{1}$ is the motor armature current in $\mathrm{A}$, and $i_{2}$ is the generator armature current in $\mathrm{A}$. For the generator of this paper, $V_{2}=R_{e} i_{2}$. Thus, (19) becomes

$$
\begin{gathered}
V_{1}=R_{1} i_{1}+L_{1} \dot{i}_{1}+k_{1} \dot{\theta}_{1}, \\
k_{2} \dot{\theta}_{2}=\left(R_{2}+R_{e}\right) i_{2}+L_{2} \dot{i}_{2}, \\
V_{2}=R_{e} i_{2} .
\end{gathered}
$$

2.4. The Final Dynamic Model. Thus, (11), (13), and (18) that represent the change between the wind energy and mechanic energy and (20) that represents the change between the mechanic energy and electric energy are considered as the wind turbine dynamic model with a rotatory tower.

Define the state variables as $x_{1}=i_{2}, x_{2}=\theta_{2}, x_{3}=\dot{\theta}_{2}$, $x_{4}=i_{1}, x_{5}=\theta_{1}, x_{6}=\dot{\theta}_{1}$, the inputs as $u_{1}=F_{2}$ and $u_{2}=V_{1}$, and the output as $y=V_{2}$. Consequently, the dynamic model of (11), (13), (15), (18), and (20) becomes

$$
\begin{gathered}
\dot{x}_{1}=-\frac{\left(R_{2}+R_{e}\right)}{L_{2}} x_{1}+\frac{k_{2}}{L_{2}} x_{3}, \\
\dot{x}_{2}=x_{3}, \\
\dot{x}_{3}=-\frac{k_{b 2}}{m_{2} l_{c 2}^{2}} x_{2}-\frac{b_{b 2}}{m_{2} l_{c 2}^{2}} x_{3}-\frac{2 \pi k_{b 2}}{3 m_{2} l_{c 2}^{2}}+\frac{\cos \left(x_{5}\right)}{3 m_{2} l_{c 2}^{2}} u_{1}, \\
\dot{x}_{4}=-\frac{R_{1}}{L_{1}} x_{4}-\frac{k_{1}}{L_{1}} x_{6}+\frac{1}{L_{1}} u_{2}, \\
\dot{x}_{6}=-\frac{\dot{x}_{5}=x_{6},}{4.5 m_{2} l_{c 2}^{2}} x_{5}-\frac{3 b_{b 1}}{4.5 m_{1} l_{c 2}^{2}} x_{6}+\frac{k_{m}}{4.5 m_{2} l_{c 2}^{2}} x_{4}, \\
y=R_{e} x_{1}, \\
u_{1}=F_{2 a}+F_{2 b}+F_{2 c}, \\
F_{2 a}=\frac{1}{2 x_{3}} \rho A C_{p}(\lambda, \beta) V_{\omega}^{3}, \\
F_{2 b}=\frac{1}{2 x_{3}} \rho A C_{p}(\lambda, \beta) V_{\omega}^{3}, \\
\frac{1}{2 x_{3}} \rho A C_{p}(\lambda, \beta) V_{\omega}^{3}, \\
F_{2 c}, \\
v_{3} R \\
V_{\omega}
\end{gathered}
$$

where $C_{p}(\lambda, \beta)$ is defined in (16) and $\lambda_{i}$ is defined in (17).

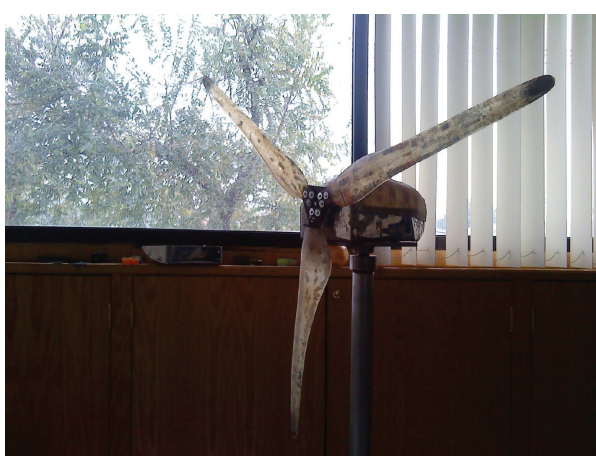

FIGURE 5: Prototype of a wind turbine with rotatory tower.

TABLE 1: Parameters of the prototype.

\begin{tabular}{lc}
\hline Parameter & Value \\
\hline$l_{c 2}$ & $0.5 \mathrm{~m}$ \\
$m_{2}$ & $0.5 \mathrm{~kg}$ \\
$k_{b 2}$ & $1 \times 10^{-6} \mathrm{kgm}^{2} / \mathrm{s}^{2}$ \\
$b_{b 2}$ & $1 \times 10^{-1} \mathrm{kgm}^{2} \mathrm{rad} / \mathrm{s}$ \\
$k_{2}$ & $0.45 \mathrm{Vs} / \mathrm{rad}$ \\
$R_{2}$ & $6.96 \Omega$ \\
$L_{2}$ & $6.031 \times 10^{-1} \mathrm{H}$ \\
$R$ & $l_{c 2} \mathrm{~m}$ \\
$\rho$ & $1.225 \mathrm{~kg} / \mathrm{m}^{3}$ \\
$g$ & $9.81 \mathrm{~m} / \mathrm{s}^{2}$ \\
$R_{e}$ & $30 \Omega$ \\
$k_{m}$ & $0.09 \mathrm{~Wb}$ \\
$k_{b 1}$ & $1 \times 10^{-6} \mathrm{kgm}{ }^{2} / \mathrm{s}^{2}$ \\
$b_{b 1}$ & $1 \times 10^{-1} \mathrm{kgm}{ }^{2} \mathrm{rad} / \mathrm{s}$ \\
$k_{1}$ & $0.0045 \mathrm{Vs} / \mathrm{rad}^{2}$ \\
$R_{1}$ & $18 \Omega$ \\
$L_{1}$ & $6.031 \times 10^{-1} \mathrm{H}$ \\
$V_{\omega}$ & $5 \mathrm{~m} / \mathrm{s}$ \\
$\beta$ & $0.5 \mathrm{rad}$ \\
\hline
\end{tabular}

Remark 1. The model of this research considers a direct current motor and a direct current generator. This wind turbine is proposed to be used on the house roof for the daily usage to feed a light as a renewable source. If more than one wind turbine is used, more electricity is generated. The proposed model could be extended to other kinds of machines by changing (20).

Remark 2. Note that the dynamic model states of the wind turbine with a rotatory tower (21) is a linear system [6-10].

\section{Experiments to Validate the Dynamic Model}

Figure 5 shows the prototype of a wind turbine with a rotatory tower which is considered for the simulations of the dynamic model. This prototype has three blades with a rotatory tower which does not use a gear box. Table 1 shows the parameters of the prototype. The parameters $m_{2}$ and $l_{c 2}$ are obtained from 

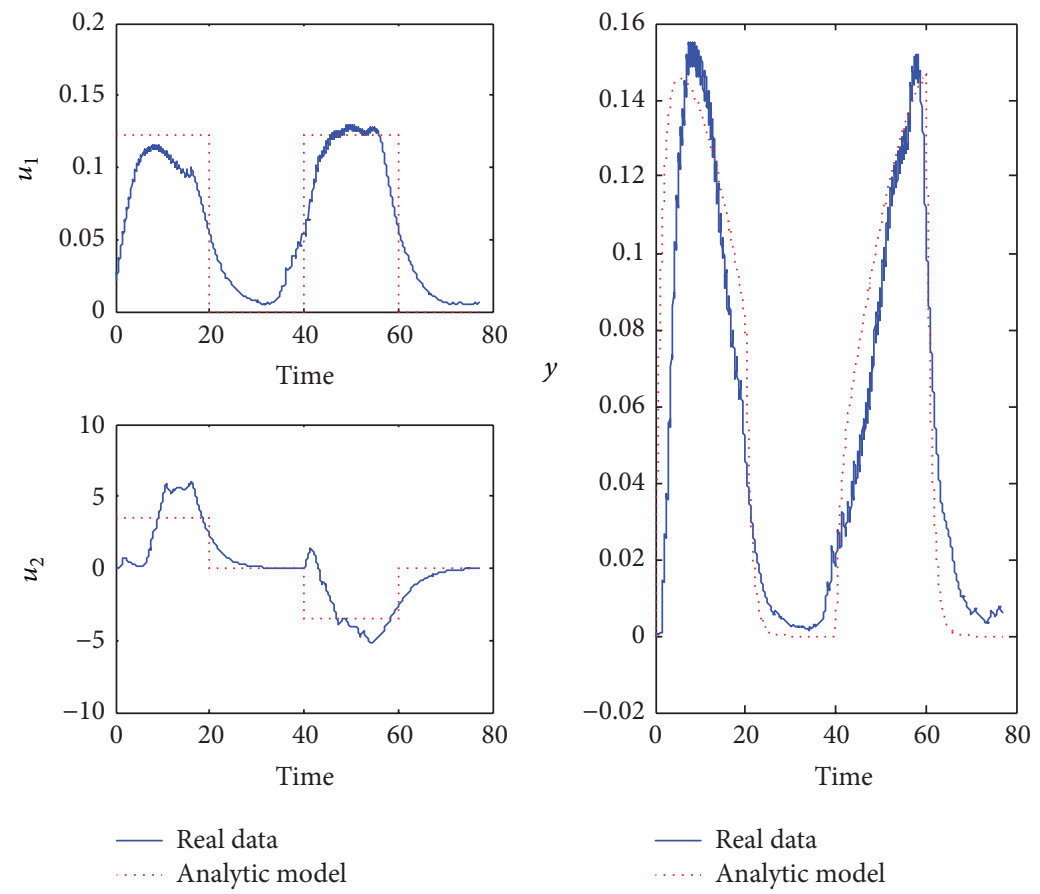

FIgURE 6: Inputs and output of the wind turbine of Example 1.

the wind turbine blades. The parameters $R_{1}, L_{1}$, and $k_{1}$ are obtained from the tower motor. The parameters $k_{2}, R_{2}, R_{e}$, and $L_{2}$ are obtained from the wind turbine generator. The parameters $R, \rho, V_{\omega}$, and $\beta$ are obtained from [2-5].

The dynamic model of the wind turbine with a rotatory tower is given by (21) with the parameters of Table $1.1 \times 10^{-5}$ are considered as the initial conditions for the plant states $x_{1}=i_{2}, x_{2}=\theta_{2}, x_{3}=\dot{\theta}_{2}, x_{4}=i_{1}, x_{5}=\theta_{1}$, and $x_{6}=\dot{\theta}_{1}$. The root mean square error (RMSE) is used, and it is given as [13-15]

$$
\operatorname{RMSE}=\left(\frac{1}{T} \int_{0}^{T} e^{2} d \tau\right)^{1 / 2}
$$

where $e^{2}=e_{u j}^{2}=\left(u_{j r}-u_{j}\right)^{2}, e^{2}=e_{x i}^{2}=\left(x_{i r}-x_{i}\right)^{2}$, or $e^{2}=$ $e_{y}^{2}=\left(y_{r}-y\right)^{2}$ and $u_{j r}, x_{i r}$, and $y_{r}$ are the real data of $u_{j}, x_{i}$, and $y$, respectively, $i=1,2, \ldots, 6, j=1,2$.

3.1. Example 1: The First Behavior. Figures 6 and 7 show the wind turbine inputs, outputs, and states. Table 2 shows the RMSE for the errors.

From Figures 6 and 7, it can be seen that the dynamic model has good behavior described as follows: (1) from $0 \mathrm{~s}$ to $2 \mathrm{~s}$, both inputs are fed; consequently, the tower moves far of the maximum air intake, the generator current is decreased, and the wind turbine blades stop moving; (2) from $2 \mathrm{~s}$ to $4 \mathrm{~s}$, both inputs are not fed; consequently, current is not generated and both the tower and wind turbine blades do not move; (3) from $4 \mathrm{~s}$ to $6 \mathrm{~s}$, both inputs are fed, but the air intake is positive and tower voltage is negative; consequently, the tower returns to the maximum air intake, the generator current is increased, and the wind turbine blades move; (4) from $6 \mathrm{~s}$ to $8 \mathrm{~s}$, both
TABLE 2: The RMSE for Example 1.

\begin{tabular}{lc}
\hline & RMSE \\
\hline$e_{u 1}^{2}$ & 0.0204 \\
$e_{u 2}^{2}$ & 1.1835 \\
$e_{y}^{2}$ & 0.0171 \\
$e_{x 1}^{2}$ & $5.7158 \times 10^{-4}$ \\
$e_{x 2}^{2}$ & 0.9843 \\
$e_{x 3}^{2}$ & 0.0470 \\
$e_{x 4}^{2}$ & 0.0658 \\
$e_{x 5}^{2}$ & 0.0872 \\
$e_{x 6}^{2}$ & 0.0163 \\
\hline
\end{tabular}

inputs are not fed; consequently, current is not generated and the tower and wind turbine blades do not move. The dynamic model is a good approximation of the wind turbine behavior because the signals of the first are near to the signals of the second. From Table 2, it is shown that the dynamic model is a good approximation of the real process because the RMSE is near to zero.

3.2. Example 2: The Second Behavior. Figures 8 and 9 show the wind turbine inputs, outputs, and states. Table 3 shows the RMSE for the errors.

From Figures 8 and 9, it can be seen that the dynamic model has good behavior described as follows: (1) from $0 \mathrm{~s}$ to $2 \mathrm{~s}$, the input air is fed and the tower input is not fed; consequently, the tower remains in the maximum air intake, the generator current is maximum, and the wind turbine blades have motion; (2) from $2 \mathrm{~s}$ to $4 \mathrm{~s}$, the air is not fed and 

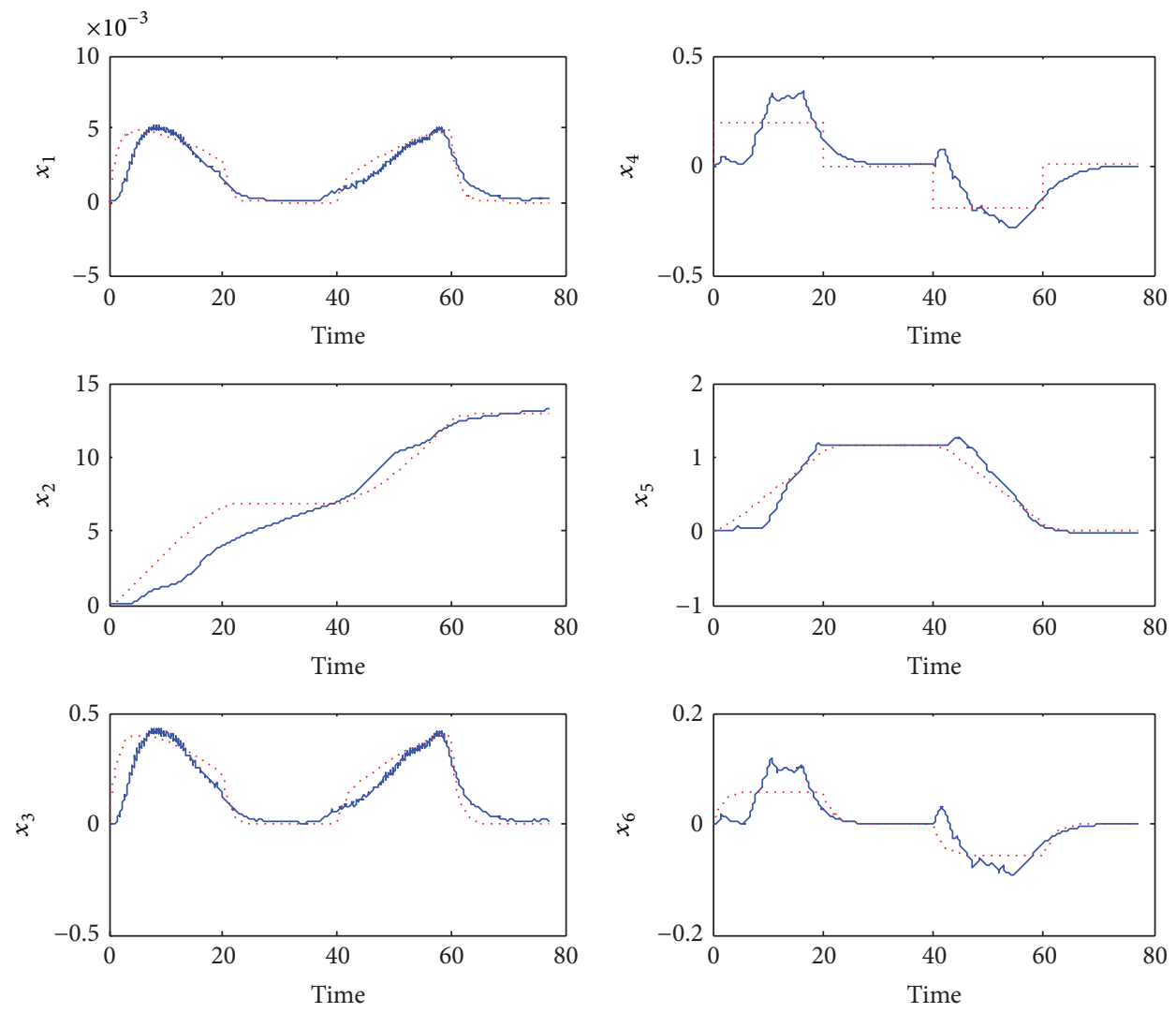

— Real data

Analytic model

- Real data

Analytic model

FIGURE 7: States of the wind turbine of Example 1.
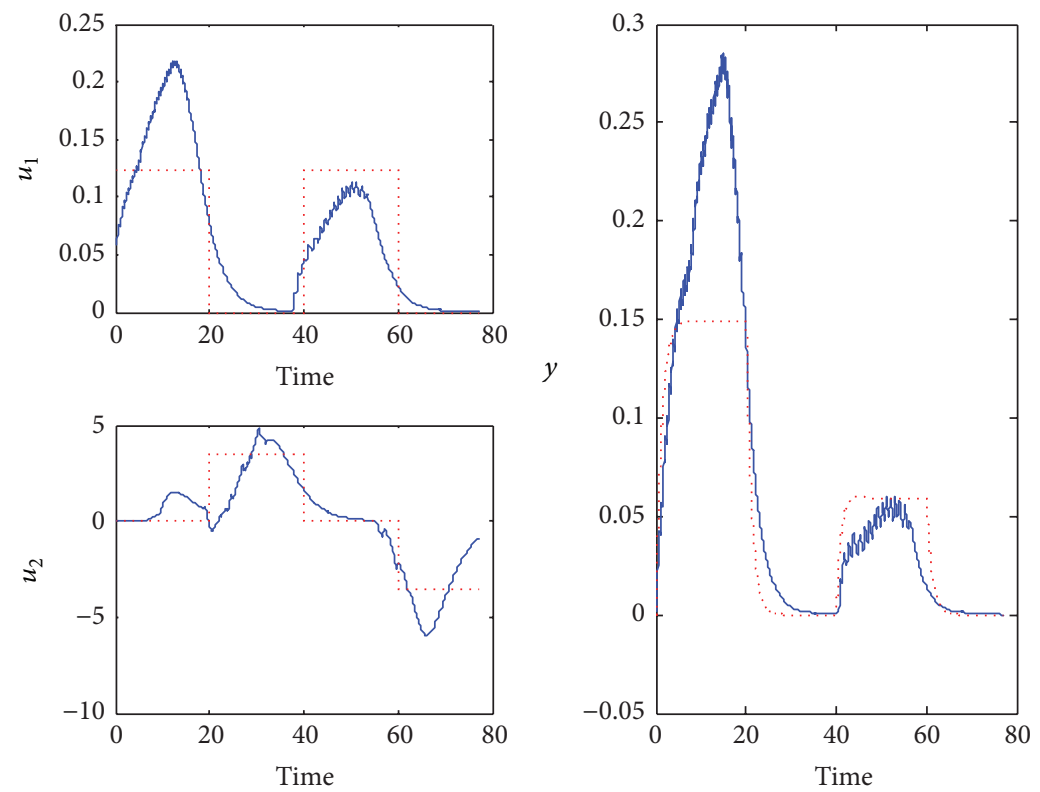

- Real data

Analytic model

FIGURE 8: Inputs and output of the wind turbine of Example 2. 

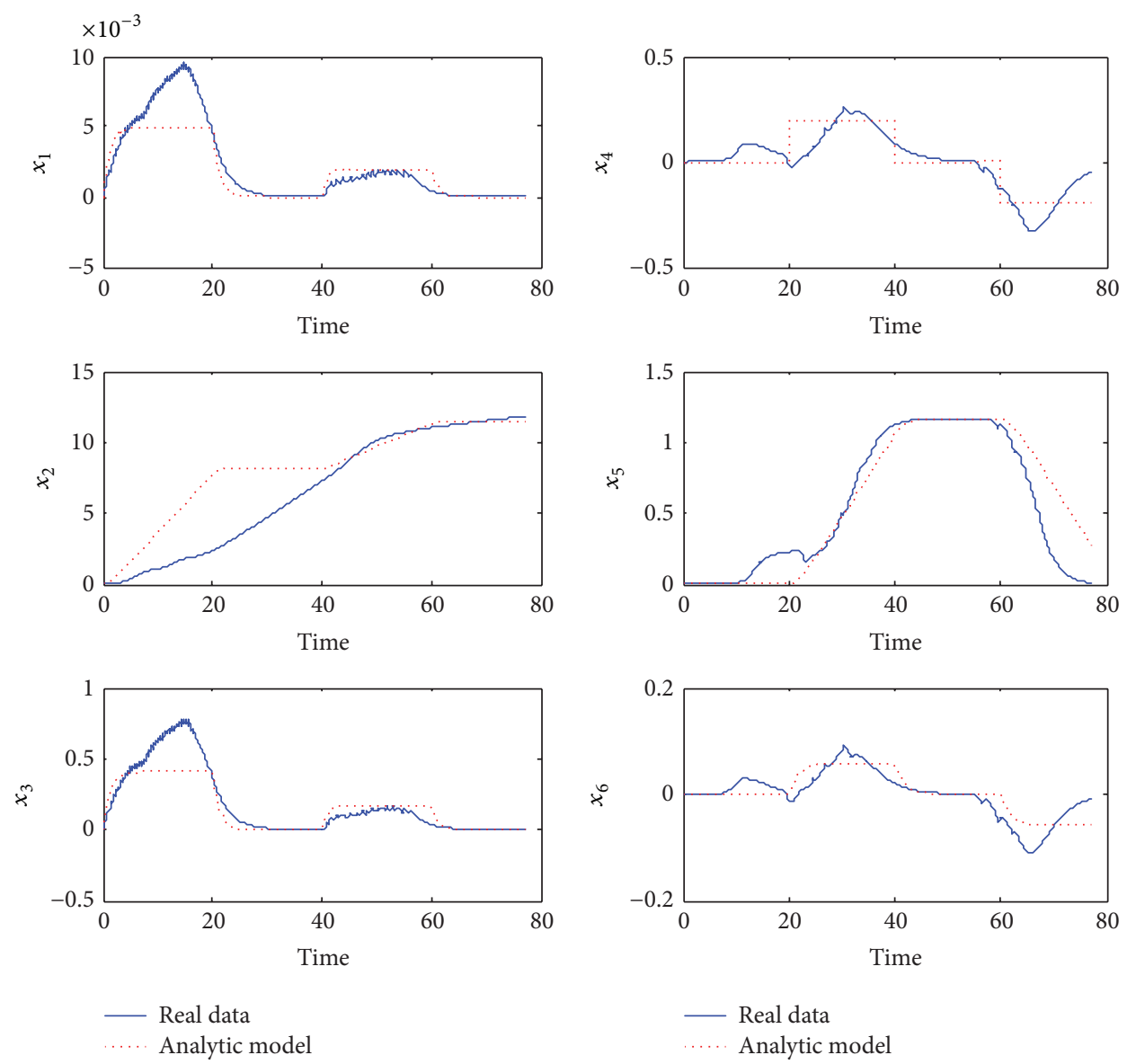

FIGURE 9: States of the wind turbine of Example 2.

TABLE 3: The RMSE for Example 2.

\begin{tabular}{lc}
\hline & RMSE \\
\hline$e_{u 1}^{2}$ & 0.0288 \\
$e_{u 2}^{2}$ & 0.9423 \\
$e_{y}^{2}$ & 0.0280 \\
$e_{x 1}^{2}$ & $9.3212 \times 10^{-4}$ \\
$e_{x 2}^{2}$ & 1.7209 \\
$e_{x 3}^{2}$ & 0.0766 \\
$e_{x 4}^{2}$ & 0.0523 \\
$e_{x 5}^{2}$ & 0.1324 \\
$e_{x 6}^{2}$ & 0.0162 \\
\hline
\end{tabular}

the tower input is fed; consequently, current is not generated, the tower moves far of the maximum air intake, and the wind turbine blades do not have motion; (3) from $4 \mathrm{~s}$ to $6 \mathrm{~s}$, the air is fed and the tower input is not fed; consequently, the tower does not move, the generator current is minimum, and the wind turbine blades almost do not move; (4) from $6 \mathrm{~s}$ to $8 \mathrm{~s}$, the air is not fed and the tower input is fed with a negative voltage; consequently, current is not generated, the tower returns to the maximum air intake, and the wind turbine blades do not have motion. The dynamic model is a good approximation of the wind turbine behavior because the signals of the first are near to the signals of the second. From Table 2, it is shown that the dynamic model is a good approximation of the real process because the RMSE is near to zero.

\section{Conclusion}

In this paper, a dynamic model of a wind turbine with a rotatory tower was introduced; the simulations using the parameters of a prototype showed that the proposed dynamic model has an acceptable approximation of the wind turbine behavior. The proposed dynamic model could be used on control, prediction, or classification. As a future research, the modeling will be improved using other interesting methods as the least squares in [16-26], neural networks in [14, 27-32], or fuzzy systems in $[15,33-35]$.

\section{Conflict of Interests}

The authors declare that there is no conflict of interests regarding the publication of this paper.

\section{Acknowledgments}

The authors are grateful to the editor and the reviewers for their valuable comments and insightful suggestions, which 
helped to improve this paper significantly. The authors thank the Secretaría de Investigación y Posgrado, Comisión de Operación y Fomento de Actividades Académicas del IPN, and Consejo Nacional de Ciencia y Tecnología for their help in this paper.

\section{References}

[1] L.-L. Fan and Y.-D. Song, "Neuro-adaptive model-reference fault-tolerant control with application to wind turbines," IET Control Theory \& Applications, vol. 6, no. 4, pp. 475-486, 2012.

[2] A. Žertek, G. Verbič, and M. Pantoš, "Optimised control approach for frequency-control contribution of variable speed wind turbines," IET Renewable Power Generation, vol. 6, no. 1, pp. 17-23, 2012.

[3] E. B. Muhando, T. Senjyu, A. Yona, H. Kinjo, and T. Funabashi, "Disturbance rejection by dual pitch control and self-tuning regulator for wind turbine generator parametric uncertainty compensation," IET Control Theory and Applications, vol. 1, no. 5, pp. 1431-1440, 2007.

[4] C. Y. Tang, Y. Guo, and J. N. Jiang, "Nonlinear dual-mode control of variable-speed wind turbines with doubly fed induction generators," IEEE Transactions on Control Systems Technology, vol. 19, no. 4, pp. 744-756, 2011.

[5] R. Vepa, "Nonlinear, optimal control of a wind turbine generator," IEEE Transactions on Energy Conversion, vol. 26, no. 2, pp. 468-478, 2011.

[6] M. Dehghan and M. Hajarian, "Modied AOR iterative methods to solve linear systems," Journal of Vibration and Control, 2012.

[7] M. Hajarian, "Matrix form of the Bi-CGSTAB method for solving the coupled Sylvester matrix equations," IET Control Theory \& Applications, vol. 7, no. 14, pp. 1828-1833, 2013.

[8] M. Hajarian, "Effcient iterative solutions to general coupled matrix equations," International Journal of Automation and Computing, vol. 10, no. 5, pp. 481-486, 2013.

[9] M. Hajarian, "Matrix iterative methods for solving the Sylvestertranspose and periodic Sylvester matrix equations," Journal of the Franklin Institute, vol. 350, no. 10, pp. 3328-3341, 2013.

[10] J. J. Rubio, G. Ordaz, M. Jiménez-Lizárraga, and R. I. Cabrera, "General solution of the Navier-Stokes equation to describe the dynamics of a homogeneous viscous fluid in an open tube," Revista Mexicana de Física, vol. 59, no. 3, pp. 217-223, 2013.

[11] F. L. Lewis, D. M. Dawson, and C. T. Abdallah, Control of Robot Manipulators, Theory and Practice, 2004.

[12] M. W. Spong, S. Hutchinson, and M. Vidyasagar, Robot Modeling and Control, John Wiley \& Sons, New York, NY, USA, 2006.

[13] J. J. Rubio, J. Pacheco, J. H. Pérez-Cruz, and F. Torres, "Mathematical model with sensor and actuator for a transelevator," Neural Computing and Applications, vol. 24, no. 2, pp. 277-285, 2014.

[14] J. J. Rubio and J. H. Perez-Cruz, "Evolving intelligent system for the modelling of nonlinear systemswith dead-zone input," Applied Soft Computing B, vol. 14, pp. 289-304, 2014.

[15] J. J. Rubio, "Evolving intelligent algorithms for the modelling of brain and eye signals," Applied Soft Computing B, vol. 14, pp. 259-268, 2014.

[16] S. Ding, R. Ding, and E. Yang, "A filtering based recursive least squares estimation algorithm for pseudo-linear auto-regressive systems," Journal of the Franklin Institute, 2013.

[17] F. Ding, "Combined state and least squares parameter estimation algorithms for dynamic systems," Applied Mathematical Modelling, vol. 38, no. 1, pp. 403-412, 2014.
[18] F. Ding, "Coupled-least-squares identification for multivariable systems," IET Control Theory \& Applications, vol. 7, no. 1, pp. 68-79, 2013.

[19] F. Ding, "Decomposition based fast least squares algorithm for output error systems," Signal Processing, vol. 93, no. 5, pp. 12351242, 2013.

[20] F. Ding, "Two-stage least squares based iterative estimation algorithm for CARARMA system modeling," Applied Mathematical Modelling, vol. 37, no. 7, pp. 4798-4808, 2013.

[21] L. Han, F. Wu, J. Sheng, and F. Ding, "Two recursive least squares parameter estimation algorithms for multirate multiple-input systems by using the auxiliary model," Mathematics and Computers in Simulation, vol. 82, no. 5, pp. 777-789, 2012.

[22] H. Hu and F. Ding, "An iterative least squares estimation algorithm for controlled moving average systems based on matrix decomposition," Applied Mathematics Letters, vol. 25, no. 12, pp. 2332-2338, 2012.

[23] X. L. Li, L. C. Zhou, R. F. Ding, and J. Sheng, "Recursive leastsquares estimation for Hammerstein nonlinear systems with nonuniform sampling," Mathematical Problems in Engineering, vol. 2013, Article ID 240929, 8 pages, 2013.

[24] S. Pan and J.-S. Chen, "A least-square semismooth Newton method for the second-order cone complementarity problem," Optimization Methods \& Software, vol. 26, no. 1, pp. 1-22, 2011.

[25] D. Q. Wang, F. Ding, and Y. Y. Chu, "Data filtering based recursive least squares algorithm for Hammerstein systems using the key-term separation principle," Information Sciences, vol. 222, pp. 203-212, 2013.

[26] D. Wang, F. Ding, and L. Ximei, "Least squares algorithm for an input nonlinear system with a dynamic subspace state space model," Nonlinear Dynamics, vol. 75, no. 1-2, pp. 49-61, 2014.

[27] J. Chen and R. F. Ding, "An auxiliary-model-based stochastic gradient algorithm for dual-rate sampled-data Box-Jenkins systems," Circuits, Systems, and Signal Processing, vol. 32, no. 5, pp. 2475-2485, 2013.

[28] J. Chen, "Several gradient parameter estimation algorithms for dual-rate sampled systems," Journal of the Franklin Institute, vol. 351, no. 1, pp. 543-554, 2014.

[29] F. Ding, X. Liu, H. Chen, and G. Yao, "Hierarchical gradient based and hierarchical least squares based iterative parameter identification for CARARMA systems," Signal Processing, vol. 97, pp. 31-39, 2014.

[30] M. Pratama, S. G. Anavatti, P. P. Angelov, and E. Lughofer, "PANFIS: a novel incremental learning machine," IEEE Transactions on Neural Networks and Learning Systems, vol. 25, no. 1, pp. 55-68, 2014.

[31] J. H. Pérez-Cruz, J. J. Rubio, J. Pacheco, and E. Soriano, "State estimation in MIMO non- linear systems subject to unknown deadzones using recurrent neural networks," Neural Computing and Applications, 2013.

[32] J. Sun, J.-S. Chen, and C.-H. Ko, "Neural networks for solving second-order cone constrained variational inequality problem," Computational Optimization and Applications, vol. 51, no. 2, pp. 623-648, 2012.

[33] A. Buchachia, "Dynamic clustering," Evolving Systems, vol. 3, no. 3, pp. 133-134, 2012.

[34] E. Lughofer, "Sigle pass active learning with conflict and ignorance," Evolving Systems, vol. 3, no. 4, pp. 251-271, 2012.

[35] L. Maciel, A. Lemos, F. Gomide, and R. Ballini, "Evolving fuzzy systems for pricing fixed income options," Evolving Systems, vol. 3, no. 1, pp. 5-18, 2012. 


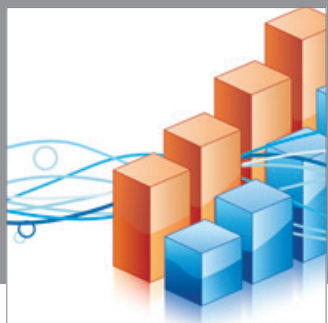

Advances in

Operations Research

mansans

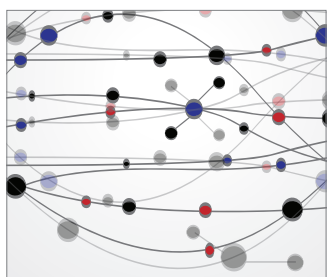

The Scientific World Journal
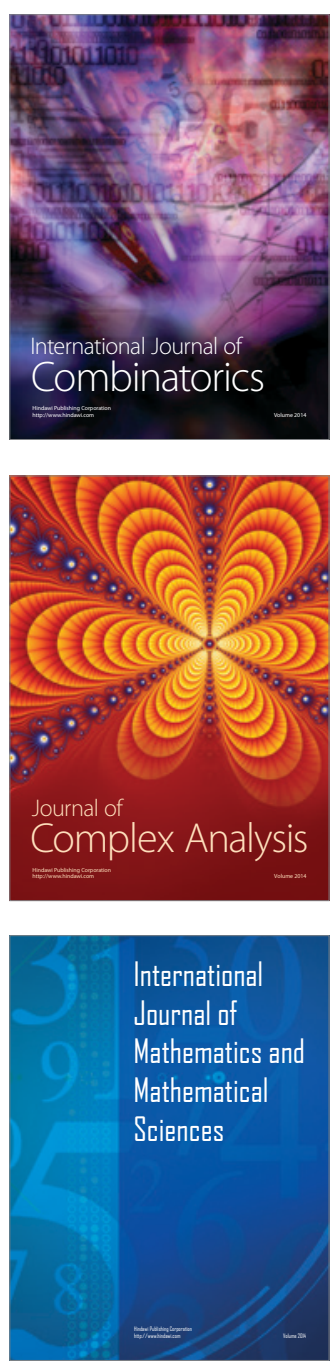
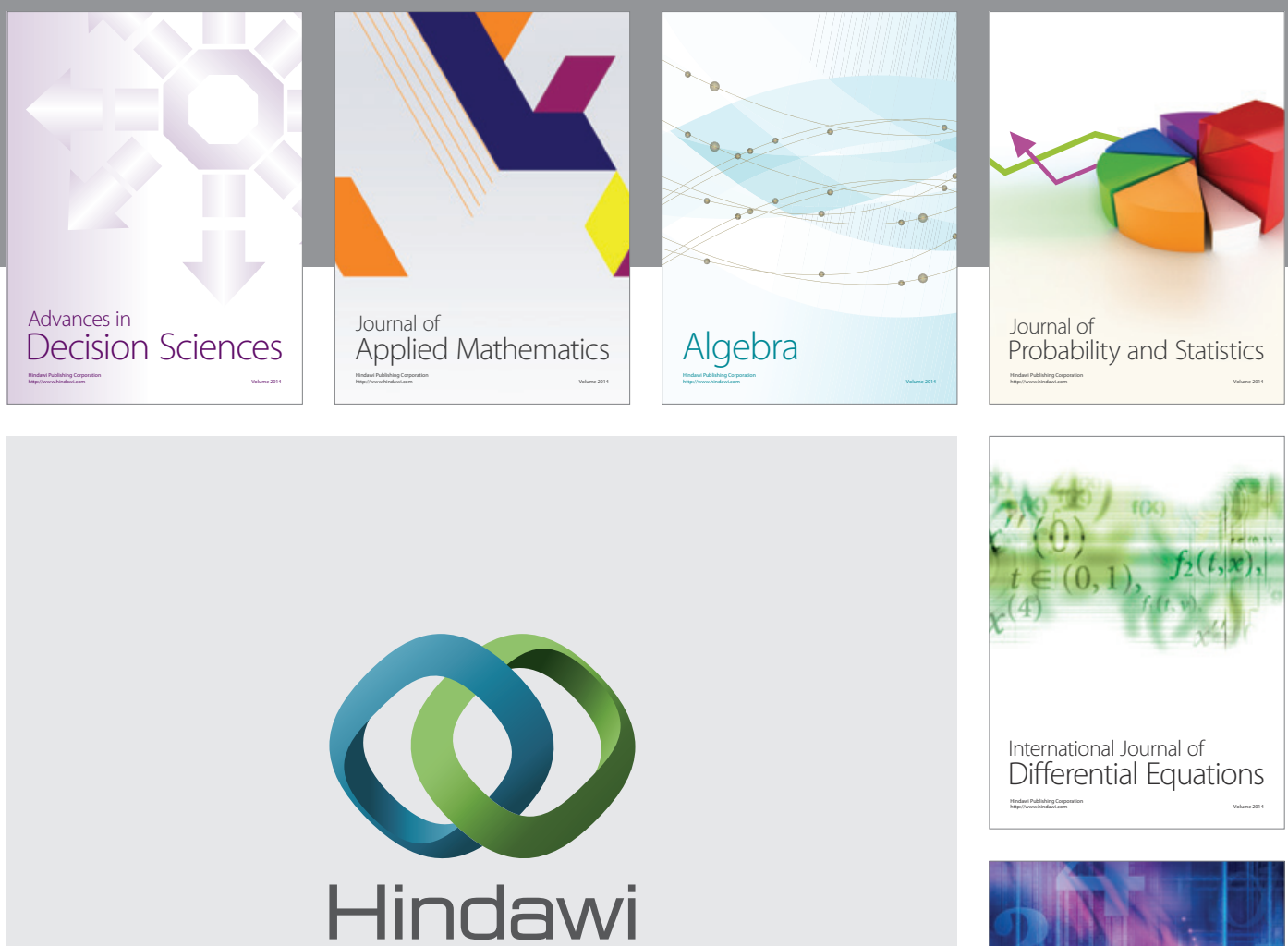

Submit your manuscripts at http://www.hindawi.com
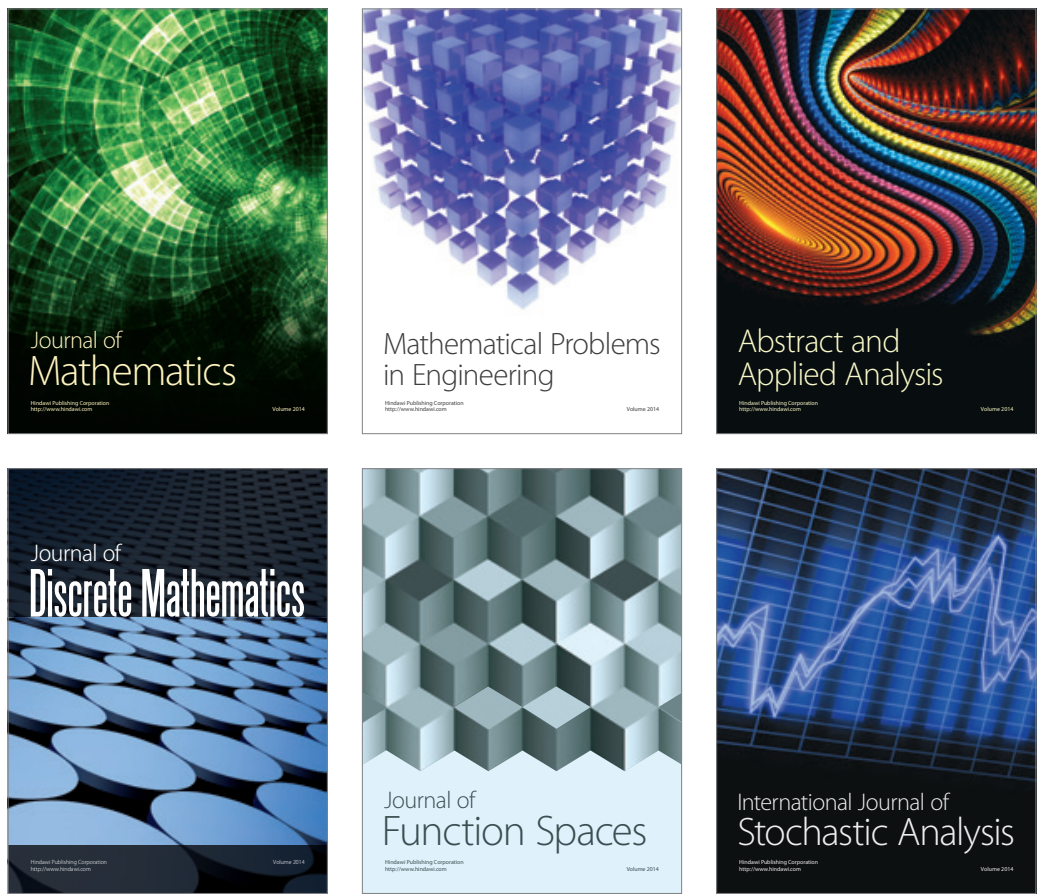

Journal of

Function Spaces

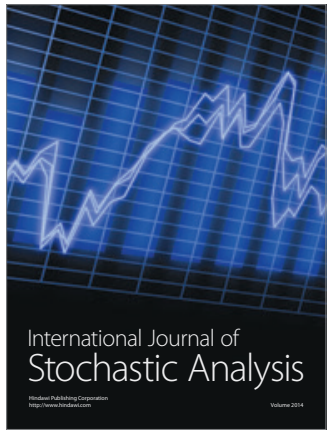

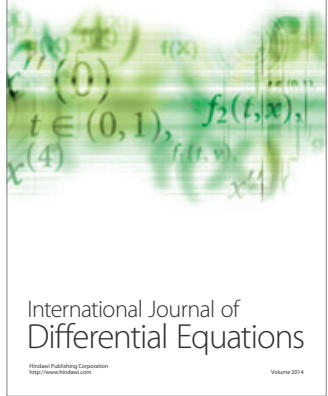
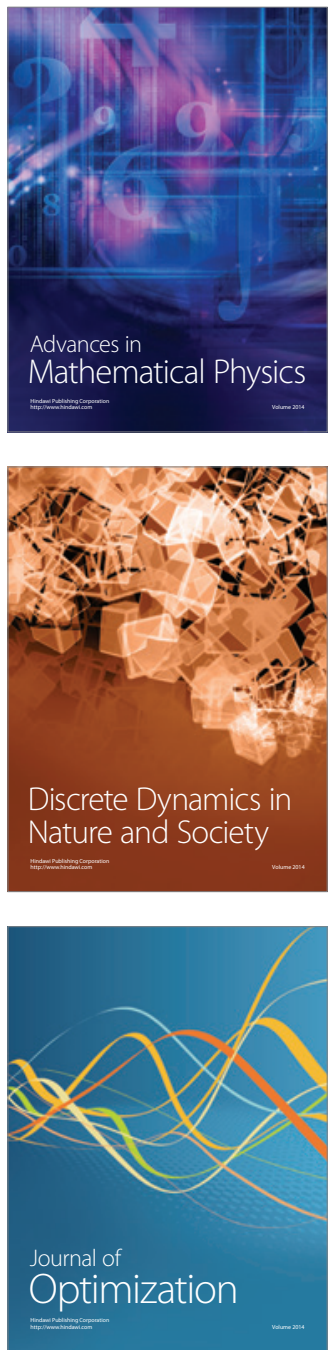